\title{
EL LIBERALISMO CLÁSICO DE JAMES M. BUCHANAN
}

\author{
Alejandra M. Salinas \\ ESEADE/UCA
}

\begin{abstract}
Resumen: Este artículo analiza el pensamiento del Premio Nobel de Economía James M. Buchanan, desagregando lo que la autora considera como sus aportes fundamentales a la teoría sociopolítica: la filosofía del individualismo, la política como intercambio y como contrato, el Estado limitado como antónimo del Estado sobreextendido, la democracia de corte individualista y constitucional, la política sin romanticismo y la constitución moral como sustrato del liberalismo clásico.

Palabras Clave: Buchanan, liberalismo, democracia, individualismo, constitucionalismo.

RECIBIDO: septiembre 2016; ACEPTADO: noviembre 2016.

\section{THE CLASSICAL LIBERALISM OF JAMES M. BUCHANAN}

AвSTRACT: This paper analyzes the thought of Nobel Prize James M. Buchanan by disaggregating his fundamental contributions to the sociopolitical theory: the philosophy of individualism, politics as exchange and as a contract, limited government as the opposite of the overextended State, an individualistic and constitutional basis of
\end{abstract}

\footnotetext{
Alejandra M. Salinas. Licenciada en ciencias políticas y relaciones internacionales y doctora en sociología por la Pontificia Universidad Católica Argentina (UCA). Profesora de teoría social y política contemporánea en la Untref, Eseade y UCA. Email: salinas22000@yahoo.com.

La autora quiere agradecer a los árbitros anónimos de Estudios Públicos por sus sugerencias y comentarios.
} 
democracy, politics without romance, and the moral constitution as the substrate of classical liberalism.

KEY wORDS: Buchanan, liberalism, democracy, individualism, constitutionalism.

ReCEIVED: September 2016; ACCEPTED: November 2016.

E octubre de 2016 se cumplieron treinta años de la entrega del Si bien es más conocido por sus numerosas contribuciones a la teoría económica, su aporte ha sido también significativo en el campo de la teoría sociopolítica. En este sentido, el autor no sólo continuó y renovó una tradición intelectual de larga data al señalar los beneficios del libre intercambio cooperativo y los aspectos económicos de las decisiones políticas, sino que además defendió la idea de un contrato constitucional que limitara estrictamente las funciones de gobierno y enfatizó los presupuestos éticos que subyacen al buen funcionamiento de las instituciones (Buchanan 1978, 216). ${ }^{1}$

Este trabajo analiza el liberalismo político del autor, desagregando lo que considero son sus aportes fundamentales: la filosofía del individualismo, la política como intercambio y como contrato, el Estado limitado como antónimo del Estado sobreextendido, la democracia de corte individualista y constitucional, la política sin romanticismo y la constitución moral como sustrato del liberalismo clásico.

Como es el caso de los autores que lo inspiraron en esta materia - principalmente Adam Smith, David Hume y James Madison-, la riqueza del pensamiento de Buchanan reside en una mirada integral de los fenómenos sociales, en tanto combinan un análisis filosófico y lógico de las instituciones políticas y económicas, un diagnóstico evaluativo de su funcionamiento, predicciones acerca de las conductas y resultados a esperar según los incentivos provistos en cada ordenamiento institucional y propuestas normativas para impedir que la realización de los proyectos colectivos se lleven adelante a expensas de los derechos y las libertades de las personas. De hecho, es este último aspecto el que lo

${ }^{1}$ Para agilizar la lectura, en adelante las referencias a los textos de Buchanan omiten el nombre del autor y los años indican la fecha de publicación original y, a continuación, la página. 
inspiró a lo largo de los años: "La relación del individuo con el Estado es, por supuesto, el tema central de la filosofía política. (...) Mi propósito fue en última instancia normativo, traté de buscar el sentido económico en la relación entre el individuo y el Estado antes que proponer panaceas políticas" (1986, sin página).

Desde este ángulo, Buchanan desarrolla teorías sobre cómo conciliar los distintos valores individuales en la vida política, de modo de asegurar en conjunto la paz, la libertad y la prosperidad. Puede decirse que las tres ideas que conforman el núcleo de su visión son: el respeto de los derechos y libertades individuales, el diseño institucional de un gobierno limitado y el reconocimiento de las bases éticas de un orden social libre. Tanto su defensa de la democracia constitucional como de la economía de mercado se asientan sobre estos tres pilares, que ocuparán mi atención en este ensayo.

Ahora bien, ¿por qué escribir aquí sobre el legado de Buchanan para la libertad? Una primera razón para contribuir con la divulgación de su obra es que el autor ofrece sólidos argumentos para refutar ciertas críticas al liberalismo. Para ilustrar algunas de esas críticas, citaré las recientes palabras de un sociólogo y profesor universitario:

Como se sabe, el ideal liberal, tanto político como económico, se funda en una célebre y falaz paradoja: los intereses individuales - es decir, el egoísmo natural de las personas - generarán una sociedad ordenada y equitativa. Esta premisa se lleva bien con la administración, pero mal con la política, por una razón obvia: omite las relaciones de poder y la lucha de intereses que rigen en la sociedad. Sólo las empresas, los mercados aldeanos y las democracias cantonales pueden darse el lujo de la paradoja liberal, no el capitalismo avanzado y las democracias de masas. (Fidanza 2016)

Como veremos más adelante, Buchanan ofrece varias herramientas para refutar la supuesta "paradoja liberal"; en su opinión, ni los intereses individuales se reducen al egoísmo, ni el liberalismo ignora la lucha por el poder. Antes bien, precisamente porque reconoce la multiplicidad de motivaciones humanas que dan pie a la ubicuidad del conflicto es que busca contener a éste mediante normas y procedimientos determinados. Por otro lado, el ideario defendido por Buchanan no sólo es 
compatible con la economía globalizada y la democracia moderna, sino que es la mayor condición de su éxito, toda vez que el buen funcionamiento de ambas se asienta en el ejercicio del derecho del individuo a tomar la decisión última sobre qué uso dar a sus libertades.

Una segunda razón para promover el pensamiento de Buchanan se relaciona con su contribución a las ciencias sociales. Si se miran los programas de las reuniones anuales de asociaciones profesionales, de inmediato se constata la abundancia de escritos que describen, comparan, miden, simulan juegos y modelos formales de la política; sólo una minoría de analistas elaboran o aplican teorías que examinen las instituciones sociales en función del valor de la libertad. Contra este contexto, Buchanan nos recuerda que "los gobiernos tienden a hacer muchas cosas, y la mayoría de ellas las hacen tontamente", y nos exige una mayor atención acerca de "lo que debe ser" un sistema de gobierno limitado (2002a, 2-4). Su análisis es principalmente una reflexión sobre preguntas como las siguientes: ¿Por qué importa la libertad?, ¿qué instituciones la promueven mejor?, ¿cuáles son las amenazas a la libertad y cómo es posible evitarlas?

Independientemente de la importancia de su espíritu normativo, la obra de Buchanan es especialmente valiosa en tiempos de acentuada especialización profesional, ya que integra métodos y aborda temas comunes a varias disciplinas. La suya, por lo tanto, es una lectura superadora de las barreras entre disciplinas, que propone abordar las interacciones entre las personas en términos de una "teoría general sobre las estructuras sociales". Una mirada más integral de la sociedad puede contribuir a hacernos comprender mejor el comportamiento humano, y en función de ello orientar el cambio político en direcciones más sensatas y realistas $(1966,265 ; 1989 b, 69)$.

Leer a Buchanan puede ser de interés por un tercer motivo. En tiempos en que gran parte de la retórica pública aspira de modo creciente a movilizar sentimientos e ideas en pos de visiones idealizadas del gobierno, el autor nos convoca a incluir criterios más rigurosos en los debates políticos. De su lectura, queda claro que ni la opresión socialista, ni el sentimentalismo populista, ni el paternalismo estatal son mecanismos legítimos y adecuados para organizar la vida social de modo efectivo. Esta conclusión resulta de especial relevancia para comprender el funcionamiento de las instituciones en América Latina. En 
las últimas décadas, las trabas crónicas de la burocracia latinoamericana son acompañadas por una creciente inseguridad y niveles complejos de corrupción política. A este escenario se suma el avance de un asistencialismo estatal cuyos efectos de largo plazo demostraron ser contrarios a los objetivos deseados. Los textos de Buchanan presentan conceptos y métodos que permiten explicar las causas y consecuencias de estas situaciones y proponer reformas a las mismas.

Tomemos, por ejemplo, la tipología del político contemporáneo como factor que ha incidido en la expansión del Estado. Encontramos en primer lugar al ideólogo, alguien que busca hacer el bien, alcanzar la "buena sociedad" en función de un criterio propio impuesto sobre los demás; en segundo lugar figura quien desea ocupar posiciones de autoridad, y en pos del poder y la fama se embarca en proyectos para satisfacer a sus electores sin atender al costo de los mismos; tercero, e igualmente preocupante, es el especulador que busca ventajas materiales personales en el cargo público a expensas del resto. Los tres perfiles tienen motivación para aumentar el gasto público como una manera de alcanzar sus objetivos y, consecuentemente, han contribuido a expandir el Estado a costa de los derechos y libertades individuales (1975, 228-231).

Por otro lado, hay quienes piensan que los gobiernos pueden resolver, mejorar o prevenir el supuesto problema del choque entre los intereses individuales y el bienestar general generado bajo el liberalismo. Buchanan encuentra fallas en este razonamiento, y señala que es incorrecto inferir que, porque los mercados puedan ser imperfectos, los procesos políticos funcionarán mejor. La comparación que sugiere efectuar es entre dos instituciones imperfectas; que el mercado falle no es razón suficiente para la intervención del gobierno (Buchanan y Brennan 1985, 128). Esta observación es medular a su programa de investigación, conocido como la "teoría económica de la política", que se extendió por más de cincuenta años y cuyo aporte fue reconocido con el Nobel.

En función de los argumentos precedentes, el ensayo está organizado en torno a los mencionados aportes fundamentales de Buchanan en el campo de la teoría sociopolítica: 1) la filosofía social del individualismo; 2) la política como intercambio y como contrato; 3) Estado limitado versus Estado sobreextendido; 4) una democracia individualista y constitucional; 5) una política sin romanticismo; y 6) la constitución moral y el liberalismo clásico. 


\section{LA FILOSOFÍA SOCIAL DEL INDIVIDUALISMO}

Una de las áreas de estudio de la filosofía social es el comportamiento humano en sociedad en términos de los valores e ideales que persiguen las personas. Buchanan no fue formado como filósofo social, pero desarrolla sus teorías a partir de una noción fuerte de individualismo que recorre toda su obra. Su análisis abarca aspectos distintos pero interrelacionados: en términos empíricos y metodológicos, los individuos son considerados unidades biológicas separadas, y son ellos quienes deben tomar decisiones en el ámbito privado (el mercado) y público (la política) en base a sus preferencias, valores e intereses (la unidad básica de decisión puede ser también la familia). En el plano moral, el autor defiende un "igualitarismo moral natural" de las personas, que se traduce en otorgar "trato igual a personas desiguales", e "igual respeto recíproco"; y en el plano sociopolítico sostiene que son los individuos quienes dan legitimidad a una estructura política mediante la idea de consentimiento voluntario. $^{2}$

Es importante señalar que el individualismo así entendido no implica retratar un individuo aislado. Por el contrario, las personas se encuentran situadas en un entorno social, en el cual influyen y son influidas por los demás, como queda claro en estos párrafos:

El individuo es la unidad única de conciencia (...) esta concepción no significa en modo alguno rechazar la influencia de la comunidad o la sociedad en el individuo. (...) La presuposición sólo requiere que las influencias sociales o comunitarias entran a través de la modificación de los valores expresados potencialmente por el individuo. (1985, 25-26)

El individuo se encuentra localizado en un tiempo y lugar, con una histórica genética y cultural, que incluye la participación en interacciones con otras personas, a quienes se les reconoce la capacidad recíproca de elegir entre restricciones y de actuar dentro de las restricciones elegidas, en sus roles de decisores-actores privados y públicos. (1989c, 452)

${ }^{2}$ Sobre la relación entre igualdad moral y política ver, entre otros, los siguientes textos de Buchanan: 2008, 104-106; 1975, 30-31; 1966, 263; 1985, 243-245; 1989b, 56; Buchanan y Tullock 1962, 23, cap. 18. 
La inserción individual en un contexto familiar y social da por tierra con la caricatura del hombre-átomo liberal, ya que lo retrata en una relación de mutuo beneficio con otros.

Un segundo aspecto a analizar en la idea de individualismo es el proceso de formación de las preferencias, elaboradas en base a un criterio personal o en base a criterios externos a los cuales cada individuo adhiere. ${ }^{3}$ Adoptar el individualismo como método de estudio implica reconocer una diversidad de motivaciones, preferencias e intereses individuales. Si bien se trata de un individuo en un esfuerzo constante para aumentar su bienestar material, ello no significa afirmar que la única motivación sea pensar y actuar sólo en provecho propio y con fines utilitarios, porque también se lo contempla como alguien que muestra otros intereses (1966, 253-254). Debe subrayarse el ánimo prudencial con que Buchanan construye su teoría política a partir de estos postulados, tono que late en esta cita:

El desafío que se nos plantea es el de construir, o reconstruir, un orden político que canalice el comportamiento egoísta de los participantes hacia el bien común de modo que se acerque lo más posible a lo que nos describió Adam Smith en relación al orden económico. $(1978,216)$

Por lo tanto, en la medida en que se pueda describir y explicar al menos una parte de las conductas humanas, y predecir qué tipo de actitudes han de esperarse en un contexto institucional dado, el supuesto utilitario ofrece una perspectiva válida, que coexiste con muchas otras (1983a, 122; 1988b, 81; 1989b, 69; Buchanan y Tullock 1962, 46).

En este sentido, Buchanan advierte reiteradamente que la idea de una persona preocupada por aumentar su riqueza no tiene contenido normativo (es decir, no es una recomendación), sino que sólo reviste carácter metodológico: la gente simplemente tenderá a elegir más antes que menos de aquello que consideren como bueno. En su esfuerzo por obtener más, intentará minimizar los costos y hacer el mejor uso

${ }^{3}$ Para Buchanan no hay necesidad de una deliberación pública como instancia formadora de las preferencias individuales; éstas se toman como "dadas". En otras palabras, las personas no tienen el deber de explicar y justificar sus preferencias en el ámbito político, como sostienen las llamadas teorías deliberativas. Ver, entre éstas, Amartya Sen (2009, 321-354). 
posible de los recursos disponibles. Esta conducta es esperable tanto en la esfera de sus actividades privadas - tales como intercambiar bienes económicos y otros-, como en el ámbito público relativo al voto, informarse políticamente, etcétera (1983a, 120; 1988b, 80). Por lo tanto, en cuanto método de estudio, el individualismo no formula juicios de valor, es decir, no condena la conducta de maximización de utilidad, excepto cuando se efectúa a costa de la propiedad de los demás. Es en este último caso que el presupuesto utilitario adopta un matiz de predicción y advertencia, al afirmar que el afán material de algunos lesionará los derechos y libertades de otros. Esta predicción permite luego dar el salto normativo: para evitar la violación de derechos y libertades individuales se deben introducir restricciones constitucionales al rango de las actividades colectivas (1983a, 124; 1983b, 23; 1989b, 58-63).

La defensa del individualismo en el ámbito sociopolítico se deriva entonces de los supuestos mencionados en los párrafos anteriores:

La libertad individual se convierte en el objetivo decisivo de la política social, no como un elemento instrumental para alcanzar la dicha económica o cultural ni como un valor metafísicamente superior, sino, de manera mucho más sencilla, como consecuencia necesaria de una metodología individualista-democrática. $(1975,9)$

Es porque el individuo es la unidad de análisis y de decisión que necesita libertad para interactuar con los demás en pos de la realización de sus proyectos. El orden social del libre intercambio entre personas emerge así como una organización asentada sobre el valor del individualismo.

\section{LA POLÍTICA COMO INTERCAMBIO Y COMO CONTRATO}

Desde el punto de vista liberal, las personas deben ser libres de interactuar voluntariamente en beneficio mutuo. Si el proceso de mercado facilita la provisión de bienes y servicios mediante el intercambio económico, en la arena política se busca evitar el conflicto también a partir de un proceso mediante el cual se adoptan normas e instituciones para obtener beneficios recíprocos a través de la organización colectiva (1975, 31; 1978, 162; Buchanan y Tullock 1962, 49). En palabras de Buchanan: 
(...) la única forma de legitimar la coacción de un hombre por otro hombre es a través de un orden político en el cual se ha dado un proceso de intercambio. En última instancia, les entregamos nuestros impuestos y nuestra libertad y les permitimos que nos coaccionen porque tenemos que estar recibiendo algunos beneficios a cambio. $(2001,8)$

Afirmar que el intercambio político es de tipo cooperativo no significa pasar por alto, como se ha sugerido, las relaciones de poder y la lucha de intereses. Buchanan es taxativo en su afirmación de que no hay una "armonía natural", es decir, no hay una bondad intrínseca o un equilibrio inherente a las relaciones sociales. Por el contrario, existe el conflicto como dato inevitable, y es para proteger el intercambio pacífico que deben adoptarse normas e instituciones colectivas. En este sentido, las interpretaciones sobre el carácter conflictivo de la política son admisibles, en tanto se puedan complementar con la idea de que es posible interactuar sobre la base de un acuerdo que estipule las condiciones legítimas del intercambio entre personas (1975, 46-47, 90).

La idea de un intercambio político entre individuos que acuerdan respetar las normas a cambio de la protección de sus derechos contrasta con otras teorías contemporáneas de la política, que delinearé brevemente a continuación. En la teoría de Bertrand de Jouvenel, por citar un ejemplo, la política no se basa en un acuerdo entre iguales, sino en la capacidad de lograr "mover" a otros para cumplir lo que la voluntad del movedor se propone. No se contemplan aquí los intercambios mutuamente beneficiosos establecidos en base a los criterios de cada persona, sino que son los grupos con mayor conocimiento sobre cómo mover a los demás los que dominan al resto. Dado que así funcionan las cosas - opina este autor-, se vuelve necesario enseñar "virtud" a quienes dominan, y evitar que el conflicto inherente a la política devenga en violencia revolucionaria (De Jouvenel 1963, 46, 107-108, 215, 256).

La política como intercambio se diferencia asimismo de quienes, con Erich Fromm, encuentran en la acción política la posibilidad de llevar adelante una planificación central en la cual no hay estrictamente un intercambio, sino una imposición definida según criterios externos a quienes deben acatar la decisión. La planificación central no buscaría maximizar beneficios, sino proveer una sensación de seguridad y protección. Desde este ángulo, según Fromm, un sistema planificado 
en el que "toda la nación domine racionalmente las fuerzas sociales y económicas" puede combinarse con la creatividad y la cooperación de las personas, asegurando resultados más deseables que el intercambio social no planificado centralmente (Fromm 1941, 299-301).

Por su parte, la teoría populista de Ernesto Laclau, por citar un último ejemplo, reduce el accionar político a la disputa por el poder de manera antagónica y conflictiva. El populismo sería una de las formas de ese antagonismo, que emerge del discurso de un líder cuestionando una dinámica institucional vista como insuficiente u opresiva. La lógica populista consiste en la articulación por parte del líder de las demandas insatisfechas y, en caso de tener éxito, en la construcción de un poder hegemónico que opere contra los "enemigos" del pueblo. El autor argentino critica el "mito" de la sociedad reconciliada y defiende el populismo como una forma de pensar la política global contra la "dominación capitalista" (Laclau 2005, 87, 283-288, 293).

Consideradas en conjunto, las teorías apologistas del puro poder, de la planificación central y del populismo rechazan la idea del consentimiento individual que subyace al intercambio político, y que son la base de su legitimidad en la medida en que permite a los individuos obtener lo que esperan conseguir de los demás de un modo voluntario, dentro de un marco legal determinado en base a criterios compartidos. El consentimiento mediante el intercambio es reemplazado en estas teorías por la dominación, la planificación y el antagonismo, respectivamente, y las normas, instituciones y procedimientos son reemplazados por la discrecionalidad y la fuerza de quien posea el mando. En contraste, Buchanan advierte que donde no haya un intercambio político dentro de un marco institucional se producirá inestabilidad, estancamiento y pérdida de la libertad individual $(1997,230)$. No sorprende a nadie constatar que los regímenes políticos basados en la dominación dictatorial, la planificación socialista y el antagonismo populista hayan producido todos o algunos de estos resultados allí donde fueron implementados.

Ahora bien, las condiciones del intercambio social están dadas por un acuerdo constitucional fundacional que otorgue legitimidad al orden político. Hay que evaluar y justificar las instituciones, normas y decisiones políticas a la luz del valor del individualismo y de los procesos de intercambio entre personas libres. Justificar es aquí la palabra clave, 
e implica reconocer que "ponerse de acuerdo" es una idea preferible a otras ideas alternativas sobre cómo organizar políticamente una sociedad. El contrato está justificado si satisface los deseos individuales, satisfacción que constituye una suerte de "interés general". Así entendido, el principal objetivo de la idea del contrato constitucional es definir los derechos individuales y proteger el intercambio entre las personas en base a esos derechos (1975, 29-31, 121-124, 126-134).

La legitimidad del contrato está dada por el consentimiento individual, que opera como una cláusula hipotética, "como si” las personas otorgaran su consentimiento al momento de adoptar o reconocer un acuerdo constitucional. El supuesto "como si" se deriva de una teoría política según la cual las personas deben ser los decisores últimos que dan legitimidad a las decisiones colectivas (1966, 253; 1985, 250). Por lo tanto, los intercambios subsecuentes al contrato serán legítimos según el grado en que lo respetan. Nótese que un mismo criterio de legitimidad - el acuerdo voluntario entre las partes - se aplica a la política en su instancia constitucional, tanto como a las prácticas políticas posteriores al contrato.

Además de definir derechos para proteger los intercambios voluntarios, existen otras dos funciones del contrato pensadas para la etapa postconstitucional: autorizar a la mayoría a tomar ciertas decisiones colectivas, y poner restricciones sustantivas y procedimentales a éstas. Las analizaré más adelante, luego de señalar dos aclaraciones sobre la teoría del contrato aquí presentada. En primer lugar, no se debe entender el contractualismo como una afirmación histórica acerca del origen de los gobiernos. De hecho, Buchanan admite que la mayoría de los gobiernos no emergieron del acuerdo entre hombres iguales sino de la coerción y la conquista (1993a, 192). Su teoría no imagina un contrato adoptado en un momento ni una sociedad en particular, como tampoco es una descripción de las acciones o conductas observables en el marco de un sistema dado, ni mucho menos una característica de los sistemas constitucionales actuales. Antes bien, su versión del contractualismo sirve para evaluar instituciones y decisiones colectivas (existentes o no), y justificarlas a la luz del valor de la libertad individual $(1975,85)$.

Una segunda aclaración derivada de la anterior es que el enfoque contractualista es compatible con cualquier análisis histórico que examine los procesos en que las constituciones han sido creadas o reforma- 
das en las diversas sociedades a lo largo del tiempo. Buchanan así lo reconoce al admitir que una constitución es "una compleja red de normas, precedentes, convenciones e instituciones", que puede surgir de varias maneras: de la simple evolución de las prácticas políticas y legales existentes, de la selección explícita en un momento histórico dado e, incluso, de la imposición por la fuerza de las autoridades $(2000,11)$. Por esta razón, el contrato constitucional tampoco debe entenderse como una postura que defiende una ruptura con el pasado, ya que puede muy bien asentarse en una tradición de costumbres y documentos que van dando forma y voz a lo que luego constituirán las cláusulas fundamentales de una constitución.

Si el contrato no puede explicar por sí solo el origen de las normas colectivas, es una idea muy útil para pensar y justificar cualquier cambio político. Sólo la idea de un contrato asentado en el consentimiento individual otorga legitimidad a un cambio en las "reglas del juego" de una sociedad. De este modo, el contrato opera como una restricción a las decisiones colectivas, justificadas en base al valor del individualismo $(1975,85 ; 1978,209)$. Para ponerlo en términos menos abstractos: consentir significa aceptar algo. Si todos los miembros de un grupo aceptan algo, decimos que hay unanimidad en una elección. Cuando las decisiones colectivas siguen el principio de unanimidad, toman en consideración la opinión de cada uno de los miembros de ese grupo. La razón para adoptar el principio de unanimidad como regla de votación es porque damos valor al individualismo. En el esquema conceptual de Buchanan, el ideal individualista para las reglas de decisiones colectivas es la unanimidad; es sólo por razones pragmáticas que las decisiones colectivas se pueden tomar de acuerdo a una regla de mayoría, pues de otra manera serían muy costosas de implementar. Volvemos aquí sobre la necesidad de las restricciones: dado que la regla de mayoría implica que las minorías se verán obligadas a acatar decisiones que no comparten, se hace necesaria una norma última que restrinja el campo de las decisiones políticas, de modo de proteger derechos y libertades individuales (1975, 72-73).

La dirección que tome la dinámica postconstitucional permitirá que el contrato tenga vigencia o no. ¿De qué factores depende el éxito del contrato constitucional? Según Buchanan, dependerá de que las acciones individuales presenten una combinación adecuada de elementos 
ético-culturales (como la voluntad de respetar el libre intercambio) y elementos políticos (como voluntad de acatar la ley, proteger los derechos y sancionar las violaciones a éstos). La "actitud constitucional" se vuelve entonces un factor crítico para dar sustento al contrato (1975, $120 ; 1982,50)$.

\section{ESTADO LIMITADO VERSUS ESTADO SOBREEXTENDIDO}

Toda "constitución de la libertad" establece los principios y normas fundamentales para la asignación y protección de los derechos individuales, el diseño de la estructura de un Estado limitado y la forma de organizar las decisiones colectivas de un modo restrictivo. En palabras de Buchanan, el "Estado protector" surge como una institución pensada para hacer cumplir las leyes fundamentales que el contrato indica, y penalizar su violación. Resulta crucial comprender que las agencias del Estado protector no definen los derechos, sino que sólo los hacen respetar, ya que quienes definen los derechos son los individuos contratantes. En tal sentido, los funcionarios públicos a cargo de la provisión del servicio de protección de derechos operan como lo hacen los árbitros en un partido de fútbol, velando por el cumplimiento de las reglas del juego, pero sin definirlas (1975, 109, 121-23; 1977, 175).

Buchanan utiliza un lenguaje económico para desarrollar un argumento político: afirma que cuando los derechos sean efectivamente protegidos, una sociedad poseerá un "bien público de capital”, es decir, se encontrará en una situación que facilita y abarata los intercambios individuales mutuamente beneficiosos. El contrato garantiza el ejercicio de los derechos; en cierta forma, funciona como una amenaza para que quienes no respetan los derechos de los demás resulten castigados. A la inversa, cuando los derechos no se vean protegidos, cuando los infractores al contrato y a las leyes derivados de él no sean castigados, existirá un "mal público" que debilitará progresivamente el orden social, generando una situación que perjudica a todos (1983a, 113; Buchanan y Brennan 1980, 221-225).

En un esquema liberal, el Estado estará limitado a cumplir con la función de protección así entendida. Ahora bien, cuando vaya más allá y cumpla otro tipo de funciones, el Estado tenderá a sobreextenderse. Según Buchanan, tal es el caso del Estado benefactor actual, el Estado 
redistribuidor y el Estado socialista. Mientras este último pretende crear valor a partir de una economía centralizada que provee a la población bienes y servicios en forma directa, el Estado benefactor actual provee un conjunto de transferencias netas de seguridad inicialmente pensadas para ayudar a gente en extrema pobreza, pero gradualmente extendidas a otros fines. Por su parte, el Estado redistribuidor toma dinero de unos grupos y no se los da a quienes más lo necesitan, sino a otros grupos y por diversos motivos (por ejemplo, subsidiando al sector agrícola) (1988a, 3-14).

A la luz de varios regímenes políticos latinoamericanos del siglo XXI, puede decirse que el Estado populista ha devenido en una forma combinada del Estado benefactor, redistribuidor y socialista. Comparte con el socialismo la desconfianza en el espíritu y los resultados de los procesos de libre intercambio individual; con el Estado redistribuidor, el otorgamiento de subsidios a sectores que no los necesitan; y con el Estado benefactor, un exceso de asistencialismo paternalista. Independientemente de estas afinidades, lo que caracteriza al populismo y lo diferencia de las otras modalidades de Estado sobreextendido es su objetivo: no busca promover un igualitarismo de resultados sociales, sino, como mencionamos antes, crear un antagonismo entre grupos para asegurar la continuidad del proyecto populista. De todos modos, las críticas al Estado sobreextendido revisten utilidad para evaluar en qué medida el populismo produce iguales o peores consecuencias negativas, como las mencionadas a continuación.

En opinión de Buchanan, el Estado sobreextendido anuló y desmanteló las instituciones del gobierno limitado, causando un grave impacto económico y moral. Entre los efectos económicos más visibles se incluyen el despilfarro de recursos, el fin de la austeridad fiscal, un gasto público en aumento y un déficit crónico para sostenerlo, a pesar de tasas impositivas y niveles de endeudamiento crecientes (Buchanan y Wagner 1977, cap. 8 y 9).

Como las críticas económicas son más conocidas, algunas de las consecuencias sociales y morales del Estado sobreextendido merecen ser analizadas en más detalle: el perjuicio a los más desaventajados, el debilitamiento de la responsabilidad individual y la desaparición de la ética del trabajo, entre otras. Estas situaciones son mejor explicadas por medio del concepto de consecuencias no intencionales, que distingue entre las motivaciones de las acciones humanas y el resultado no pre- 
visto - y, en general, no deseado - de esas acciones. Para Buchanan, entender este concepto puede ser la "característica más distintiva del científico social" (1989b, 57).

En tal sentido, el Estado sobreextendido ha producido dos graves consecuencias negativas no intencionales: 1) los grupos a los que se quería beneficiar no sólo no reciben los beneficios, sino que además resultan perjudicados: "No es necesario que haya, en particular, ningún desplazamiento en la distribución final de los ingresos hacia los menos favorecidos. Podría suceder exactamente lo contrario"; y 2) quienes sí reciben los beneficios dejan de esforzarse por sí mismos y se vuelven dependientes: "Aquellos que reciben transferencias de efectivo tienen menos incentivo de trabajar para obtener ingresos, y en especial debido a que, y si, la elegibilidad para transferencias se reduce a medida que se perciben los ingresos" (1988a, 3).

Seguramente el lector pueda pensar en varias situaciones que ilustran estas consecuencias. Sobre las transferencias regresivas que perjudican a quienes en realidad debieran ser los beneficiarios, cabe mencionar el caso de la universidad pública gratuita: en Argentina, por ejemplo, los estudiantes universitarios de clase media alta están siendo financiados por una mayoría de gente más pobre que no ingresa a la universidad o no se gradúa. Lo mismo puede decirse de quienes utilizan líneas aéreas estatales o reciben subsidios para la producción cinematográfica.

Un problema adicional es que la dinámica del Estado benefactor actual ha extendido su accionar beneficiando a actores que sí pueden valerse por sí mismos, ocasionando la desaparición de la ética del trabajo debido al desincentivo que introduce el asistencialismo crónico. Hay quienes, repitiendo la tan conocida letanía marxista, piensan que el trabajo moderno es una forma de explotación capitalista que ocasiona toda suerte de males: "En la sociedad capitalista, el trabajo es la causa de toda degeneración intelectual, de toda deformación orgánica" (Lafargue 1883); "Es falso que el trabajo dignifique (...) La verdadera humanización de nuestras sociedades está en el ocio" (Martín 2012). Contra és-

${ }^{4}$ Las opiniones contra el trabajo en la sociedad capitalista son defendidas en la actualidad por algunos académicos. Ver, entre otras fuentes, la entrevista a Daniel Raventós (profesor de economía de la Universidad de Barcelona) realizada por Nuria Alabao: "El trabajo no dignifica, dignifica la existencia material garantizada", Contexto y acción 47, 13 de enero de 2016. Para un tratamiento más extenso del tema ver la reedición de González Casanova (1969). 
tas y otras opiniones similares, Buchanan rescata el mensaje de la ética del trabajo, que tiene beneficios morales y económicos. Su razonamiento es sencillo: el trabajo es un recurso productivo, que es utilizado para crear valor; a la inversa, el ocio tiene un costo. En la medida en que ese costo dañe o deba ser afrontado por terceros, el ocio es inmoral y debe desalentarse. En la medida en que el trabajo produce efectos positivos sobre terceros al crear valor, la ética del trabajo debe alentarse (1994b, 370; 1991a, 364).

Llevando el argumento a favor de la ética del trabajo hasta sus últimas implicancias, inferimos que si el trabajo es creador de propiedad, y la propiedad es creadora de riqueza, debe protegerse la propiedad privada como una forma de alentar el trabajo y las cualidades éticas asociadas a él. No hay espacio aquí para elaborar más sobre las ideas de Buchanan respecto de la propiedad privada, por lo que me limitaré a señalar una lectura que el autor hace de León XIII en Rerum Novarum. Si bien la fuente puede parecer un tanto extemporánea, me interesa este texto en particular porque creo que refleja la inquietud del autor por encontrar en fuentes diversas una defensa del valor de la cultura del trabajo y de la propiedad. Buchanan resalta el lugar otorgado a estos valores en la encíclica:

(...) las personas desean poseer derechos de propiedad, con el fin de poder asegurar y mantener la libertad de disponer de los recursos, sin la cual no habría esperanza de mejorar las condiciones de vida, [de ahí] el valor que las personas depositan en la independencia que sólo un régimen de propiedad privada puede ofrecer. $(1993 b, 51)^{5}$

¿Cómo revertir las consecuencias negativas del Estado sobreextendido? Excede el objetivo de este trabajo detallar las recetas para volver a un Estado limitado, pero se pueden señalar algunas: introducir límites constitucionales al gasto público, un equilibrio presupuestario, una mayor disciplina fiscal y la no financiación del déficit con deuda, son algunas de ellas (1994c, 445; Buchanan y Wagner 1977, 95-106; 110-125;

${ }^{5}$ En este sentido, Buchanan piensa que el liberalismo no es posible cuando la mayoría de las personas son "dependientes, oportunistas, poco inteligentes y demasiado tolerantes" $(2008,19)$. 
129-149). El profesor de Virginia también propone adoptar un sistema de transferencias constitucionales ("constitutional welfare state") para evitar la discrecionalidad en la redistribución, propia de las votaciones políticas mayoritarias. El sistema se negociaría a nivel constitucional, y gira en torno a la propuesta de reducir el costo de quienes financian las transferencias, y aumentar el beneficio de quienes las reciben (1985, 249; 2008, 46; 1975, 258; Buchanan y Brennan 1985, 139-140).

\section{UNA DEMOCRACIA INDIVIDUALISTA Y CONSTITUCIONAL}

¿Es posible ser un individualista, un liberal y un demócrata al mismo tiempo? Viktor Vanberg resume la interrelación entre estos tres conceptos, a la que adscribe Buchanan:

(...) el liberalismo y la democracia comparten como su fundamento normativo común el ideal de la soberanía individual; sus respectivos focos principales - el principio liberal de la autonomía privada y el principio democrático de la soberanía ciudadana- pueden ser mejor entendidos como aplicaciones del ideal de la soberanía individual al ámbito de la sociedad de derecho privado, por un lado, y al ámbito "público" de la elección políticocolectiva, por el otro. (Vanberg 2008, 158)

En mi opinión, hablar de "soberanía individual" es una expresión que retrata bien la idea liberal de un individualismo fuerte con derecho a tomar las decisiones últimas. En tanto miembro de una comunidad política, es la "soberanía del votante" la que sustenta en última instancia una democracia. En esta sección abordo el concepto de democracia en Buchanan, su diagnóstico sobre el funcionamiento de la democracia actual y el diseño institucional que propone el autor para afianzar un sistema político individualista y constitucional.

En el centro de todo modelo democrático está la igualdad política, que otorga a cada ciudadano el derecho de participar en una decisión colectiva en igualdad de condiciones con los otros. Basada en las ideas de la "soberanía del votante" e "igual soberanía individual", la democracia constituye un mecanismo político para expresar los valores que sustentan los individuos respecto de lo público. Para Buchanan, la participación en una decisión colectiva democrática se puede dar en dos 
niveles: el acuerdo constitucional — donde se definen cuestiones sustantivas (derechos y estructuras políticas) y procesales (reglas de votación, elección y rotación en cargos de gobierno, etcétera) - y la dinámica política postconstitucional que se desarrolla a partir de esas elecciones. En esta sección nos ocuparemos de este último aspecto.

Dado que las preferencias y valores individuales son diversos, y además cambiantes, el sistema democrático permite una mayor oferta de programas y propuestas políticas, ampliando las opciones y la libertad de elegir para el votante. De esta manera, la regla de mayoría para las votaciones sirve para asegurar que distintas alternativas que compitan entre sí puedan ser aprobadas $(1979,314 ; 1985,267-271 ; 1954,97 ; 1982,40)$.

Afirmar que la democracia es una competencia de opiniones que son seleccionadas por la regla de la mayoría no significa que esa mayoría represente la voluntad general, ni la voz del pueblo o de la verdad. En este sentido, la noción de política como verdad resulta tan nociva como la noción de política como conflicto $(1967,235) .{ }^{6}$ Buchanan insiste en que la democracia es un sistema de conciliación de opiniones: la alternancia de mayorías es un mecanismo político que permite reconciliar preferencias y valores distintos en un intento por evitar conflictos entre individuos, sin aludir a ningún otro propósito. En la medida en que las votaciones mayoritarias sean cambiantes, el sistema permite que haya "ciclos" en los que distintas opiniones roten en el poder. Desde esta perspectiva, la democracia como forma de rotación de propuestas políticas es el ordenamiento que funciona mejor cuando se lo compara con otras alternativas $(1967,240)$.

Parece redundante a esta altura decir que la competencia democrática debe realizarse en base a restricciones constitucionales, de modo que los individuos retengan sus libertades individuales frente a las decisiones políticas coercitivas (1966, 263; 1978, 209; 1997, 225). Sin embargo, es oportuno enfatizar este punto, pues es el componente liberal-constitucional de la democracia buchaniana, que busca restringir la acción de mayorías y minorías por igual. Por un lado, las restricciones constitucionales son necesarias precisamente porque las elecciones competitivas y periódicas no son suficientes para proteger los derechos

${ }^{6}$ Las decisiones mayoritarias no producen verdades. La idea de que hay una verdad por descubrir en política es una idea "hegeliana" que Buchanan rechaza $(1987,70)$. 
individuales frente a las mayorías legislativas. Pensar lo contrario es incurrir en la falacia electoral y asumir que "mientras los partidos y los políticos compitan en elecciones libres y periódicas, sujetas a votaciones de mayoría o plurales, bajo el sistema de sufragio universal, no es necesario aplicar abiertamente limitaciones al radio de acción de la actividad gubernamental" (1982, 48-50). Esto es precisamente el diagnóstico de Buchanan sobre el funcionamiento de las legislaturas, que a pesar de haber generado coaliciones cambiantes han incurrido en constantes excesos presupuestarios, aumentado la intervención gubernamental y barrido con la idea de un Estado limitado.

Por otro lado, Buchanan alerta también contra las versiones elitistas de la democracia. Su crítica va dirigida contra los intelectuales y las élites legislativas y judiciales, cuyas visiones sobre la "buena sociedad" no representan las opiniones individuales, sino sus propias creencias respaldadas con poderes discrecionales. En particular, el autor cuestiona el elitismo de la "supremacía" judicial (1975, 130, 237-239). ${ }^{7}$ El problema que encuentra no es el elitismo como preferencia valorativa (ya que debiera respetarse como una preferencia más), sino su impacto institucional al entrar en conflicto con las decisiones colectivas. Es la revisión judicial de éstas la que en principio y en la práctica debilita la legitimidad del contrato constitucional, en tanto y en cuanto éste define los contenidos y procesos a seguir en la vida democrática. Buchanan parece resentir que una minoría, la de los jueces, pueda modificar tanto la estructura constitucional como las decisiones que se siguen de ella. El rol judicial legítimo, velar por los derechos, de ninguna manera incluye la redefinición de esos derechos. ${ }^{8}$ Buchanan critica el activismo judicial,

${ }^{7}$ El siguiente párrafo ilustra bien la actitud de Buchanan hacia el elitismo: "La razón por la cual nadie prestó atención a Schumpeter es que no ofreció ninguna esperanza. Schumpeter no era un demócrata (en minúsculas), sino un elitista. Él sentía que en realidad la sociedad debería ser gobernada por una pequeña aristocracia, siempre con personas como él a cargo" $(2001,3)$. Sobre su hostilidad a las élites, ver Brennan y Munger (2014, 334-335).

${ }^{8}$ Confróntese con Carlos Nino (1996, 277, 279, 293), quien defiende una revisión judicial de las decisiones democráticas y propone la participación judicial en el proceso legislativo mediante la declaración de las omisiones y errores por parte de los cuerpos representativos. Nino también cree que la revisión judicial puede descalificar leyes basadas en visiones morales "perfeccionistas", y propone la posibilidad de que los jueces tengan un "veto suspensivo" de leyes o declaren la "inconstitucionalidad por omisión" cuando las legislaturas no implementen prescripciones constitucionales. 
ya que no encuentra aceptable que existan restricciones a las decisiones colectivas legítimas. En términos actuales, cuestiona la supremacía "contramayoritaria" del poder judicial, que tiene la última palabra en materia de definiciones sobre el alcance de las decisiones políticas. Considerando la diversidad de preferencias individuales y el principio de igualdad política, al igual que otros funcionarios públicos, los jueces debieran estar sujetos a controles democráticos $(1975,150-151)$.

Un nuevo diseño institucional se hace necesario entonces para reintroducir límites a mayorías y minorías por igual. En opinión de Buchanan, una democracia liberal puede incorporar formas de decisión como el referéndum para limitar y controlar a los dos grupos. Su propuesta se enmarca dentro de la democracia participativa, que define como "los derechos de las personas a tomar sus propias decisiones colectivas". En su opinión, una democracia que incluya la posibilidad del referéndum puede complementar las decisiones de los representantes, y actuar como un dispositivo para limitar y controlar al gobierno. También puede limitar el accionar de los grupos de presión, ya que es más fácil organizar coaliciones para el intercambio de favores entre pocos legisladores que entre un electorado numeroso $(1975,35 ; 2000)$.

Como cierre de esta sección, quisiera señalar la relevancia para América Latina del sistema democrático, individualista y constitucional que delinea Buchanan. Por un lado, su defensa de tal sistema es bienvenida en una región donde democracia y liberalismo no siempre se dieron la mano. Hay un segundo aspecto a resaltar en las aplicaciones de la teoría democrática de Buchanan, y es la inclusión de mecanismos como el plebiscito para introducir o fortalecer los límites a los gobiernos. En tal sentido, la salida de Pinochet del poder, la apertura al libre comercio en Costa Rica y los intentos de referéndum revocatorio en Venezuela sirven como instancias democráticas directas para revertir situaciones restrictivas de los derechos y libertades individuales provenientes de cualquier régimen de gobierno.

\section{HACIA UNA POLITICA SIN ROMANTICISMO}

Una de las expresiones de Buchanan que ha tenido más repercusión es la de "política sin romanticismo", una perspectiva que modela los actores políticos "como seres humanos y no como ángeles", pues 
sólo de esta manera parece "posible incorporar en forma plausible la realidad de los fracasos gubernamentales" (2001, 4; 1982, 49; 1978, 217, respectivamente). ${ }^{9}$

La política sin romanticismo - también conocida como teoría económica de la política o teoría de la elección pública (public choice theory) — es un método que describe, predice y evalúa el funcionamiento de las instituciones sociales en base a los incentivos individuales de sus tomadores de decisiones (1980, 27-28; Buchanan y Brennan 1981, 86; 1985, 155). La principal idea es que los actores tenderán a pensar en satisfacer su interés propio antes que en promover el bien público. En el caso de las instituciones gubernamentales, la teoría económica de la política contempla la existencia de "fallas de gobierno", entendidas como una menor equidad y eficiencia producto de un modelo de funcionario público así retratado (1979, 306; 1983a, 113). En otras palabras, el gobierno es visto como un Leviatán, una entidad enorme y amenazante que oprime a los individuos, antes que como una entidad para el ejercicio de la benevolencia o la sabiduría. Por esa razón, los teóricos económicos de la política como Buchanan no buscan asesorar a los gobernantes, sino predecir cuáles serán sus peores cursos de acción y proponer maneras para evitarlos (1994c, 444; Buchanan y Brennan 1980, cap. 10).

Las áreas en las que se ha aplicado mayormente el concepto de fallas de gobierno son en los estudios sobre la burocracia gubernamental, los grupos de presión y los legisladores. Se afirma así que las burocracias y agencias de gobierno tenderán a incrementar las regulaciones y trámites para autojustificar su empleo o para generar más recursos fiscales; que los grupos de presión procurarán aprovechar las oportunidades creadas por la política, dirigiendo su inversión hacia alternativas menos eficientes que las procuradas por el mercado; y que los legisladores tenderán a aumentar sus ingresos y a incurrir en prácticas legislativas que producen ineficiencias o pérdidas netas en el uso de los recursos de un país. Al observar estos resultados, Buchanan utiliza el concepto de consecuencias no intencionales para explicar de

\footnotetext{
${ }^{9}$ Buchanan reconoce que la teoría económica de la política no es una perspectiva nueva, sino una reelaboración del pensamiento de autores clásicos como Adam Smith y los padres fundadores norteamericanos, que desconfiaban del gobierno y querían limitarlo.
} 
qué manera la estructura monopolista de las actividades de gobierno genera incentivos individuales que ocasionan perjuicios generales sin proponérselo $(1980,104)$.

Otro de los temas de la teoría de la elección pública es la "búsqueda de rentas". Ella alude al uso de la política como un juego de distribución en el que hay una lucha competitiva por la captura de beneficios especiales. Mientras el proceso de búsqueda de ganancias en el mercado es creador de valor, por el contrario, la búsqueda de rentas es ineficiente, ya que, como mencionamos, no genera ningún valor sino despilfarro. El problema se agrava con la expansión del gobierno, ya que éste ofrece más oportunidades para buscar rentas. Según Buchanan, "debemos esperar que el comportamiento maximizador de utilidad de los individuos los llevará a gastar más y más recursos en tratar de asegurar para sí las 'rentas' o 'beneficios' prometidos por el gobierno" (1978, 211-212).

Además de describir cómo fallan los gobiernos, la política sin romanticismo tiene importantes implicancias normativas, en tanto sugiere líneas de acción para reformar las instituciones políticas, propósito que según Buchanan quizás sea el aspecto más relevante de la teoría: evitar brindar oportunidades a burócratas, legisladores y buscadores de rentas para maximizar su riqueza a expensas del resto de la sociedad. El presupuesto analítico que guía cualquier reforma es que de no existir restricciones y controles para evitar que conductas discrecionales, favoritismos y sobornos emerjan, se detecten y sancionen, éstos se multiplicarán. En particular, Buchanan recomienda adoptar normas constitucionales específicas para limitar la búsqueda de rentas y los privilegios y favores asociados a ellas, y proteger así los derechos individuales frente a las decisiones que tomen los agentes políticos en esa dirección (1979, 308; 1988b, 88; 2001, 8-11).

Lamentablemente, el impacto de los aportes de la teoría de la elección pública ha sido limitado. En palabras de Buchanan: “... todavía tienen que penetrar en la conciencia pública. El cambio de perspectiva requiere que el fracaso del gobierno en las actividades regulatorias se contraponga a los argumentos sobre las fallas de mercado de quienes idealizan la acción colectiva" (2005). Cabe preguntarnos si la razón por la que no ha tenido mayor alcance y adhesión reside acaso en su visión poco atractiva de los actores políticos. Buchanan toma 
en consideración este aspecto: si bien se distancia de la mentalidad romántica — que asocia a los funcionarios públicos con una inclinación benevolente para servir al bien común_-, también se aparta de la mentalidad que encuentra en todos los actores políticos una tendencia a buscar solamente ventajas personales, y que se desliza hacia el anarquismo o hacia la resignación $(1979,317$; 1988b, 89). Por el contrario, para Buchanan es posible encontrar un punto intermedio entre ambas posturas — entre el idealista y el cínico-, y aceptar, por un lado, que existen actores políticos que se aprovechan de los demás, e intentar restringirlos, $y$, por el otro lado, reconocer que hay lugar para una filosofía sobre el bien público y la buena sociedad en base a reglas morales compartidas (1983a, 125-26; Buchanan y Brennan 1985, 156).

\section{LA CONSTITUCIÓN MORAL Y EL LIBERALISMO CLÁSICO}

He dejado para el apartado final el tratamiento de la cuestión moral en los textos aquí bajo análisis. Ya en El cálculo del consenso, escrito en 1962 junto con Gordon Tullock, Buchanan recalca la importancia de la responsabilidad individual de tomar en consideración el largo plazo y los efectos que sus decisiones tienen sobre otros, como una disposición moral que "puede ser una condición necesaria para el funcionamiento de cualquier sociedad de individuos auténticamente libres" (1962, 343). En Los límites de la libertad, Buchanan vuelve sobre la idea de que uno de los preceptos morales más importantes es la obediencia a la ley, pero advierte que esta disposición puede "erosionarse rápido" (1975, cap. 7). Décadas más tarde, escribe que las virtudes mínimas para sostener la constitución liberal son la responsabilidad individual, el respeto mutuo y la reciprocidad $(2008,19)$. El hincapié en la importancia de las reglas morales de conducta a la hora de interactuar en la democracia y en el mercado no ha sido lo suficientemente resaltado en la literatura secundaria, a pesar de que constituye la piedra basal de su edificio intelectual.

Del mismo modo que una comunidad se da una constitución política, las personas también tienen una constitución moral y eligen actuar en base a ella. La constitución moral funciona a la manera de cimientos que sustentan el respeto por las normas y los derechos. Fiel a su indi- 
vidualismo, el código moral tal como lo entiende Buchanan no es algo impuesto ni externo a las personas, sino que éstas internalizan las normas morales como preferencia propia, y lo hacen porque en algún punto observan que la conducta ética es conveniente para evitar el conflicto (1994a, 93-94). El código moral que manda respetar las leyes permite que las personas se comporten de un modo más cooperativo. Al fin y al cabo - razona Buchanan-, si el consentimiento contractual es una promesa de acatar las normas, la vida constitucional necesita asentarse sobre una cultura ética en la que se valore el cumplimiento de las promesas (Buchanan y Brennan 1985, 114).

Se ha señalado que existe una tensión en Buchanan entre su postulado utilitarista (maximizar riqueza) y su retórica de la constitución moral, y que el autor debiera reconocer que es el conjunto de virtudes morales, y no el interés propio, lo que en última instancia sustenta la obediencia a la norma (McCloskey 2006). A mi juicio, el respeto de las normas no requiere elegir entre una u otra disposición: la internalización de la moral puede obedecer al interés propio tanto como a la autorrestricción en su formulación cristiano-kantiana (2008, 15; Buchanan y Tullock 1962, 343). Frente a la posibilidad de cumplir o no cumplir con la ley, la lógica del interés propio dictará no infringir las normas en base a un cálculo de probabilidad de detección y castigo (y la eventual pérdida de utilidad que ello implica), mientras que la lógica de la autorrestricción dictará cumplir con la norma porque es lo que debe hacerse, simplemente para respetar al otro. ${ }^{10}$ En ambos casos, a pesar de la diferente motivación, la conducta será la misma.

Debo reconocer que el componente ético en la esfera pública adquiere mayor fuerza cuando Buchanan analiza la actitud constitucional, llegando incluso a afirmar que cada ciudadano tiene la obligación ética de sustentar una "responsabilidad" que vaya más allá del interés propio y entrar en el "diálogo constitucional". En sus palabras, "informarse y participar en la discusión de las normas constitucionales

${ }^{10}$ Es interesante constatar la aplicación empírica de estos debates en algunas encuestas de opinión. En un estudio sobre cultura constitucional, el 44 por ciento de encuestados argentinos respondió que respeta la ley por ser un deber moral; el 37, porque ello beneficia a todos; el 9, para no perjudicar a la familia y amigos; el 8 , para evitar castigos; y el uno por ciento, para no ser criticado por los demás. Ver Hernández et al. (2005, 83-85). 
debe reflejar la presencia de algún precepto ético que trasciende el interés racional del individuo" (1989a, 369, 371). Creo, sin embargo, que el mandato de entrar en el diálogo constitucional emerge de las circunstancias históricas en que el autor escribe y no de la lógica de su modelo político. Dado que Buchanan lamenta la sobreextensión del Estado - fenómeno que presencia como observador cercano-, intenta persuadir a sus contemporáneos sobre la necesidad de una reforma constitucional que reintroduzca los principios del liberalismo clásico. Sus esfuerzos se vuelven más intensos cuanto mayor es la indiferencia o el rechazo de su audiencia, académica u otra. Volver a las bases liberales del contrato implica, para él, recuperar la fe en el individuo y sus valores, y fortalecer la constitución moral necesaria para el ejercicio de la libertad.

A pesar de su diagnóstico pesimista sobre la situación actual, Buchanan invita a emprender esfuerzos para cambiar ese estado de situación: "Las instituciones del orden social se pueden reformar y cambiar. Proporcionar esa esperanza pareciera ser una obligación moral por parte del filósofo social" (Buchanan y Brennan 1985, 33). El lenguaje de la esperanza permea así sus escritos e ilumina su propósito normativo. ¿Es su visión acaso algo ingenua, como Buchanan mismo recrimina a los idealistas románticos? Quizás haya quienes piensen que sí. En mi opinión, las dos visiones no son análogas: la visión con esperanza se cimienta en la posibilidad de cambiar un estado de cosas sobre la base de un diagnóstico realista, de un acuerdo constitucional y de un pronóstico cauto respecto del alcance de cualquier reforma. En contraste, la visión ingenua aspira a implementar cambios para alcanzar resultados "imaginados", con expectativas desmedidas y sin restricciones en las formas y procedimientos que esos cambios adopten.

Quisiera concluir el ensayo con una frase que ha sido el núcleo de las preocupaciones del liberalismo clásico, y por lo tanto de Buchanan: "¿Cómo controlamos a los que controlan? (...) No hemos resuelto el problema" (2001, 12). Al respecto, el tono esperanzador de Buchanan sugiere un curso de acción para los interesados en estudiar y promover la libertad individual y en trabajar para limitar y controlar al gobierno: seguir intentándolo. 


\section{REFERENCIAS}

Alabao, Nuria. 2016. "El trabajo no dignifica, dignifica la existencia material garantizada". Contexto y acción 47 (13 de enero). https://goo.gl/tlQNtV.

Brennan, Geoffrey \& Michael Munger. 2014. "The Soul of James Buchanan?” The Independent Review 18 (3): 331-342.

Buchanan, James M. (1954) 1999. "Social Choice, Democracy and Free Markets". En The Logical Foundations of Constitutional Liberty. The Collected Works of James M. Buchanan Vol. 1, 89-102. Indianapolis: Liberty Fund. ${ }^{11}$

. (1966) 2001. "An Individualistic Theory of Political Process." En Moral Science and Moral Order, CW Vol. 17, 251-265.

- (1967) 1999. "Politics as Science: Reflections on Knight's Critique of Polanyi”. En CW Vol. 1, 230-243.

- (1975) 2009. Los límites de la libertad. Entre la anarquía y el Leviatán. Montevideo: Liberty Fund / Katz Editores.

(1977) 2001. "Criteria for a Free Society: Definition, Diagnosis and Prescription". En Federalism, Liberty and the Law, CW Vol. 18, 173-184.

(1978) 1980. "De las preferencias privadas a una filosofía del sector público". Estudios Públicos 1: 203-218.

- (1979) 1998. "Política sin romanticismos. Esbozo de una teoría positiva de la elección pública y de sus implicancias normativas". En La democracia en sus textos, con Rafael Del Águila, Fernando Vellespín y otros, 305-318. Madrid: Alianza. http://goo.gl/ko5krB.

- (1980) 1999. "Rent Seeking and Profit Seeking". En CW Vol. 1, 103-115.

1982. "Democracia limitada o ilimitada". Estudios Públicos 6: 37-51. http://goo.gl/QzYhHj.

(1983a) 2000. "The Achievements and the Limits of Public Choice in Diagnosing Government Failure and in Offering Bases for Constructive Reform”. En Politics as Public Choice, CW Vol. 13, 112-126.

- (1983b) 2000. "The Public Choice Perspective". En CW Vol. 13, 15-24.

(1985) 2001. "Political Economy and Social Philosophy". En CW Vol. 17, $235-250$

- 1986. "The Constitution of Economic Policy". Discurso de recepción del Premio Nobel. http://goo.gl/KthHx4.

. (1987) 2001. "Justification of the Compound Republic: The Calculus in Retrospect". En Choice, Contract and Constitutions, CW Vol. 16, 68-75.

1988a. "Consecuencias económicas del Estado benefactor". Libertas 8: 3-14. http://goo.gl/YTdaco.

. (1988b) 2000. "Is Public Choice Immoral?". En Politics as Public Choice, CW Vol. 13, 79-89.

${ }^{11}$ En adelante abreviado $C W$, con su respectivo volumen. 
. (1989a) 1999. "The Ethics of Constitutional Order". En CW Vol. 1, 368373.

. (1989b) 2001. "Rational Choice Models in Social Sciences". En CW Vol. $17,55-70$.

- (1989c) 1999. "Relatively Relative Absolutes". En CW Vol. 1, 442-454.

. (1991a) 2000. "Economic Interdependence and the Work Ethic". En $C W$ Vol. 12, 343-365.

- (1991b) 1999. "Foundations for Normative Individualism". En CW Vol. 1, 281-291.

. (1993a) 2001. "The Individual as Participant in Political Exchange". En Federalism, Liberty and the Law, CW Vol. 18, 185-197.

- 1993b. Property as a Guarantor of Liberty. The John Locke Institute Shaftesbury Papers 1. Vermont y Hants: Edward Elgar Publishing.

_. (1994a) 2001. "Choosing what to choose". En CW Vol. 17, 80-95.

. (1994b) 2000. "The Economics and the Ethics of Idleness". En CW Vol. $12,366-376$.

. (1994c) 2001. "Notes on the Liberal Constitution". En CW Vol. 16, 439448.

. (1997) 2001. "Democracy within Constitutional Limits". En CW Vol. 16, 225-234.

- 2000. "Direct Democracy, Classical Liberalism, and Constitutional Strategy". Presentado en la reunión de la Sociedad Mont Pèlerin, Chile.

—. 2001. "Mi peregrinaje intelectual". Conferencia en la Universidad Francisco Marroquín. 19 de enero. http://www.hacer.org/pdf/Buchanan1.pdf (También disponible en Lecturas de historia del pensamiento económico, compilado por Adrián Ravier. Madrid: Unión Editorial, 2014).

_.2002a. "El Cálculo del consenso: 40 años después... y contando". Apuntes de Economía y Política 1 (7): 2-4.

—. (2002b) 2004. "Salvando el alma del liberalismo clásico". Instituto Cato. http://goo.gl/XCBTt8.

- 2005. "Three Amendments: Responsibility, Generality, and Natural Liberty". Cato Unbound. 4 de diciembre. http://goo.gl/tXaOa9.

- 2008. Why I, Too, Am Not a Conservative: The Normative Vision of Classical Liberalism. Cheltenham, UK: Edward Elgar Publishing.

Buchanan, James M. \& Gordon Tullock. (1962) 1993. El cálculo del consenso: fundamentos lógicos de la democracia constitucional. Barcelona: PlanetaAgostini.

Buchanan, James M. \& Richard Wagner. (1977) 2000. Democracy in Deficit: The Political Legacy of Lord Keynes. En CW Vol. 8.

Buchanan, James M. \& Geoffrey Brennan. (1980) 1987. El poder fiscal. Barcelona: Ediciones Folio.

- (1981) 2000. "The Normative Purpose of Economic Science". En: Economic Inquiry and Its Logic, CW Vol. 12, 70-86. 
(1985) 2000. The Reason of Rules: Constitutional Political Economy. En CW Vol. 10.

De Jouvenel, Bertrand. (1963) 2000. The Pure Theory of Politics. Indianapolis: Liberty Fund.

Fidanza, Eduardo. 2016. "Las chances de una lógica política alternativa". $L a$ Nación. 21 de mayo. http://www.lanacion.com.ar/1900941-las-chances-deuna-logica-politica-alternativa.

Fromm, Erich. (1941) 1974. Miedo a la libertad. Buenos Aires: Amorrortu.

González Casanova, Pablo. (1969) 2006. Sociología de la explotación (nueva edición corregida). Buenos Aires: Clacso. https://goo.gl/LycWm6.

Hernández, Antonio María, Daniel Zovatto \& Manuel Mora y Araujo. 2005. Encuesta de cultura constitucional. Argentina: una sociedad anómica. México: UNAM / Asociación Argentina de Derecho Constitucional e Idea Internacional.

Laclau, Ernesto. (2005) 2009. La razón populista. Buenos Aires: Fondo de Cultura Económica.

Lafargue, Paul. (1883) 2008. "El derecho a la pereza". Marxists Internet Archive. https://www.marxists.org/espanol/lafargue/1880s/1883.htm.

Latinobarómetro. 2010. Quince años de monitoreo en 18 países de América Latina (1996-2010). Santiago de Chile.

Martín, Luisgé. 2012. "Elogio de la pereza”. El País, 31 de mayo. http://elpais.com/ elpais/2012/05/29/opinion/1338317588_867296.html.

McCloskey, Deirdre. 2006. "Hobbes, Rawls, Nussbaum, Buchanan, and All Seven of the Virtues". The First James Buchanan Lecture, George Mason University, 7 de abril. http://www.deirdremccloskey.org/articles/ bv/buchanan.php.

Nino, Carlos Santiago. (1996) 2003. La constitución de la democracia deliberativa. Barcelona: Gedisa.

Sen, Amartya. 2009. The Idea of Justice. Cambridge: Harvard University Press.

Vanberg, Viktor. 2008. "On the complementarity of liberalism and democracy: a reading of F.A. Hayek and J.M. Buchanan". Journal of Institutional Economics 4 (2): 139-161. EP 